\title{
International Bone Marrow Transplant Registry
}

National Cancer Institute

\section{Source}

National Cancer Institute. International Bone Marrow Transplant Registry. NCI

Thesaurus. Code C106372.

An international research org anization based in Milwaukee, Wisconsin that collects and analyzes data of recipients of allogeneic and autologous hematopoietic stem cell transplants. 